\title{
Análise da evolução de conflito ambiental em um aterro sanitário na Paraíba, Brasil
}

O Aterro Sanitário de Puxinanã (ASP), no estado da Paraíba, Brasil, tem sido o centro de conflitos ambientais ao longo de sua instalação, operação e desativação. Vários fatores contribuíram para a eclosão desses conflitos, podendo citar: a falta de participação pública no processo de licenciamento ambiental desse empreendimento; a localização desfavorável do aterro, a poucos metros do principal manancial que abastece o município de Puxinanã-PB; a disposição dos Resíduos Sólidos Urbanos (RSU) do município de Campina Grande-PB no ASP, com população superior a de Puxinanã em mais de 30 (trinta) vezes. O conflito abordado neste estudo tem sido avaliado em duas fases, antes e após o fechamento do ASP, com consequente disposição dos RSU de Campina Grande e Puxinanã no Aterro Sanitário de Campina Grande (ASCG), a partir de julho de 2015. Neste artigo foi analisado o conflito ambiental referente ao ASP, após sua desativação, e consequente operação do ASCG, por meio da aplicação de metodologias de análises de conflitos, que auxiliaram na compreensão das novas tensões, das coalizões entre os atores envolvidos e dos desdobramentos deste conflito. Os resultados da análise realizada convergem para os seguintes pontos: o fechamento do ASP se configurou apenas como uma resolução parcial do conflito, em sua primeira fase (2012 a meados de 2015); a desativação do aterro, sem um plano de encerramento de suas atividades e recuperação da área degradada, evidencia a fragilidade da governança ambiental; o prejuízo à população de Puxinanã-PB, em função do passivo ambiental na área e entorno do empreendimento.

Palavras-chave: Disposição final de Resíduos Sólidos; Desativação de Aterro Sanitário; Metodologias de Análise de Conflitos.

\section{Analysis of the evolution of environmental conflict in landfill located at Paraíba state, Brazil}

\begin{abstract}
The Puxinanã Landfill site (ASP), in the Paraíba state, Brazil, has been the center of environmental conflicts since its installation, during operation and after deactivation. Several factors contributed to the outbreak of these conflicts, including: the lack of public participation in the environmental licensing of this enterprise; the unfavorable location of the landfill, a few meters from the main water source that supplies the municipality of Puxinanã-PB; the placement of the urban solid waste (RSU) of the city of Campina Grande-PB in ASP, with a population greater than Puxinanã's in more than 30 (thirty) times. The conflict addressed in this study has been evaluated in two phases, before and after the closing of ASP, with consequent dumping of municipal solid waste (RSU) of Campina Grande and Puxinanã in the Campina Grande Landfill (ASCG), since July 2015. In this paper was analyzed the environmental conflict relative to the ASP after its deactivation, and consequent beginning of the ASCG operation, through the application of conflicts analysis methodologies, which helped on the understanding of the new tensions, coalitions between the players involved and the evolutions of this conflict. The results of the analysis converge to the following points: ASP deactivation is configured only as a partial solution of the conflict, in its first phase (2012 to mid-2015); the deactivation of the landfil without a closure plan of its activities and subsequent recovery of degraded areas has shown the fragility of environmental governance; the damage inflicted to the population of Puxinanã-PB, in function of the environmental liabilities created in the area and in the surroundings of the project location.
\end{abstract}

Keywords: Final disposal of Solid Waste; Sanitary Landfill Deactivation; Conflict Analysis Methodologies.

\section{Topic: Engenharia Sanitária}

Reviewed anonymously in the process of blind peer

Maria Josicleide Felipe Guedes

Universidade Federal de Campina Grande, Brasil

http://lattes.cnpq.br/3341737489331381

mjosicleide@ufersa.edu.br

Márbara Vilar de Araújo Almeida

Universidade Federal de Campina Grande, Brasil

http://lattes.cnpq.br/2822211650286715

marbara_vilar@hotmail.com

Rosires Catão Curi

University of Waterloo, Canadá

http://lattes.cnpq.br/7625445154639508

rosirescuri@yahoo.com.br

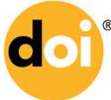

DOI: 10.6008/SPC2179-6858.2017.003.0012
Received: 01/03/2017

Approved: 01/05/2017
Referencing this:

GUEDES, M. J. F.; ALMEIDA, M. V. A.; CURI, R. C.. Análise da evolução de conflito ambiental em um aterro sanitário na Paraíba, Brasil. Revista Ibero-Americana de Ciências Ambientais, v.8, n.3, p.123-135, 2017. DOI: http://doi.org/10.6008/SPC2179-6858.2017.003.0012 


\section{INTRODUÇÃO}

A análise de conflitos ambientais é uma ferramenta necessária e desafiadora ao entendimento dos usos e apropriação de recursos de uso comum de uma determinada área em função das múltiplas causas, dimensões e atores envolvidos. Dentro desta perspectiva, quando o problema central de um conflito está associado à disposição final dos resíduos sólidos gerados pela sociedade, há de se considerar que o solo (local onde são tratados os resíduos em aterros sanitários) deixará de estar disponível para outros fins ou, pelo menos, terá restrições ao tipo de uso futuro. Além do mais, a escolha do local para a instalação e operação de aterros, quando não realizada dentro dos princípios estabelecidos pelas legislações ambientais, acaba por deteriorar outros recursos de uso comum, como a água e o ar.

Ao ser desativada uma área de um antigo aterro sanitário (ou de um lixão), esta pode vir a ser utilizada em consonância com um uso compatível, depois de adotados projetos de recuperação da área degradada. Não obstante, existe uma limitação deste uso em função dos riscos ambientais envolvidos, uma vez que a estabilização físico-química e microbiológica do maciço sanitário requer longos períodos (não inferior a 10-15 anos após o encerramento da disposição dos resíduos); só após esse período, quando estes riscos forem reduzidos a níveis aceitáveis, existe a possibilidade de destinação da ocupação do solo a um uso compatível.

A realidade atual é a dificuldade cada vez maior em aprovar novas áreas de disposição final ambientalmente adequada para os resíduos sólidos, compatível com a aceitação pública; uma vez que a proximidade a um aterro, mesmo quando bem dimensionado, acaba por desconfigurar a paisagem do entorno, com reflexos na desvalorização das terras nas proximidades desses empreendimentos.

Vários são os conflitos nessa temática ao redor do mundo, segundo Bobbio (2011), nas últimas décadas, os conflitos territoriais sobre a localização das instalações 'indesejáveis', como é o caso de aterros sanitários, que se espalharam por toda a Itália de forma violenta, sendo observados episódios semelhantes também no resto da Europa. Estes conflitos são caracterizados pelos protestos das comunidades locais que desejam defender a sua terra das agressões externas.

Em Gana, na África Ocidental, a rápida urbanização provocou uma intensa competição por terras, especialmente em áreas periféricas das grandes e médias cidades, onde os resíduos municipais eram tradicionalmente lançados. A intensa competição por terras gerou conflitos entre os diversos usos. Segundo Owusu et al. (2012), a proximidade de áreas residenciais junto aos aterros e lixões, bem como o funcionamento de aterros fora das normas ambientais, gerou hostilidade da comunidade com relação à implantação e operação desses empreendimentos. O caso de Gana é agravado pela fraca governança urbana que praticamente resulta em comunidades anfitriãs dos aterros não participarem da decisão de onde localizar e como operar um aterro sanitário.

Este tipo de conflito não se restringe ao cenário internacional. No estado da Paraíba, Brasil, a instalação e a operação do Aterro Sanitário de Puxinanã (ASP) resultaram na geração de conflitos ambientais, em função da falta de participação pública no licenciamento ambiental deste empreendimento, da localização desfavorável do aterro, a menos de $1 \mathrm{~km}$ de um importante reservatório de água para 
abastecimento público da região, somada à exportação dos RSU do município de Campina Grande para Puxinanã, que correspondia a mais de $95 \%$ dos resíduos depositados no aterro em pauta. Após três anos de disposição dos RSU de Campina Grande no ASP, houve o fechamento deste aterro e redirecionamento dos resíduos de ambos os municípios para o Aterro Sanitário de Campina Grande (ASCG).

Neste artigo foi realizada uma análise do conflito ambiental referente ao ASP após a desativação deste aterro, por meio da aplicação de metodologias de análises de conflitos, que auxiliam na compreensão das tensões, das novas coalizões entre os atores envolvidos e dos desdobramentos do conflito ambiental relativo ao Aterro Sanitário de Puxinanã/PB.

\section{METODOLOGIA}

\section{Estruturação inicial do conflito}

Definido o conflito ambiental em estudo e o período em análise (julho de 2015 a julho de 2016), este foi investigado a partir de questionamentos chave, relacionados: ao problema central do conflito, aos atores envolvidos, às possíveis coalizões e suas posições. Para dar suporte a esta etapa foi necessário realizar uma análise documental, incluindo os estudos ambientais, pareceres técnicos do órgão ambiental responsável, cartilha confeccionada por representantes da população de Puxinanã; além de visitas em campo na área em estudo.

\section{Cadeia causal}

É constituída de afirmativas que ligam as diferentes causas de um problema ambiental aos seus efeitos (MARQUES et al., 2000); sendo basicamente construída através de sucessivas respostas à questão "Por quê?" ou "Qual é a Causa?". Esta ferramenta auxilia na identificação: (a) da natureza do problema; (b) dos efeitos e consequências transfronteiriças decorrentes do problema; (c) das ligações entre o problema e suas causas; (d) das barreiras a serem removidas para solução/mitigação do problema e seus impactos.

\section{Princípios institucionais de Ostrom}

Elinor Ostrom, prêmio Nobel da Economia, realizou diversos estudos para melhor compreender aspectos institucionais da governança de recursos de uso comum, conhecidos como princípios institucionais de Ostrom (1990), sendo estes: limites claramente definidos; congruência entre regras de apropriação e provisão e condições locais; arranjos de escolha coletiva; monitoramento; sanções graduadas; mecanismos de solução de conflitos; reconhecimento mínimo dos direitos de organização; 8) iniciativa aninhada.

A análise destes princípios à luz do conflito do ASP permitirá um melhor entendimento quanto às estratégias de resolução de conflitos vinculadas ao caso em estudo, baseadas nas experiências passadas, suscitando em uma ferramenta de suporte à tomada de decisão pelos gestores ao encontro de ações mitigatórias para minimização do conflito. 


\section{Modelagem conceitual do conflito}

Os suportes metodológicos descritos nos itens anteriores deram suporte à confecção de um mapa mental, através do software InteliMap ${ }^{\circledR}$, útil na gestão de informações, compreensão e análise do conflito, bem como à modelagem conceitual do caso de estudo. Esta se constitui em uma ferramenta de suporte à tomada de decisão para o conflito relacionado ao ASP, sendo expansível para outras situações de mesma natureza.

\section{Disposição final de resíduos sólidos como raiz de conflitos ambientais}

O Panorama de Resíduos Sólidos no Brasil evidencia que 58,4\% dos RSU são destinados a aterros sanitários, correspondendo a um montante de 113.975tRSU/dia. Na região Nordeste, 455 municípios, dos 1.794 existentes, utilizam aterros sanitários como forma de disposição final dos RSU. Na Paraíba, 927tRSU/dia são destinadas a aterros sanitários, o que equivale a $31 \%$ do total de RSU diariamente gerados no estado (ABRELPE, 2014).

Este cenário é um indicativo da importância dos aterros sanitários como principal forma de tratamento e disposição final dos RSU, devido, principalmente, aos menores custos de instalação e menor complexidade de operação, quando comparados a outras formas de tratamento. Esta importância não se restringe apenas ao cenário nacional, uma vez que países como o Reino Unido, Irlanda e Estados Unidos dispõe em torno de 50\% dos RSU em aterros (LIM et al., 2007).

No sentido de legalizar as formas corretas de manejo e deposição dos resíduos sólidos foi criada a Lei Federal $n^{\circ} 12.305 / 2010$, referente à Política Nacional de Resíduos Sólidos (PNRS), que traça diretrizes para as ações a serem implementadas e exercidas pelo poder público conjuntamente com outras instâncias da sociedade a fim de minimizar a problemática dos resíduos. De acordo com a PNRS, a disposição final ambientalmente adequada dos RSU seria a distribuição apenas dos rejeitos em aterros, obedecendo às normas legais no intuito de evitar danos ou riscos à saúde pública e diminuir os impactos ambientais adversos (BRASIL, 2010).

Na dinâmica de tratamento dos RSU em aterros sanitários, possibilitada pela decomposição da fração orgânica por microrganismos decompositores, há a redução do volume dos resíduos, ocasionando deformações horizontais e verticais (recalques), além da geração de subprodutos líquidos e gasosos. Desta forma, quando operado de maneira inadequada, estes empreendimentos geram significativos impactos ambientais negativos; sendo necessário, portanto, o controle e monitoramento geomecânico e ambiental durante e após anos de encerramento das atividades de disposição de resíduos.

Por estes e outros motivos, a disposição final de RSU em aterros sanitários é, muitas vezes, responsável pela geração de conflitos ambientais, e se enquadra na categoria de empreendimentos necessários, mas ainda dentro da ótica da síndrome NIMBY "not-in-my-backyard", ou seja, "não no meu quintal". Muitas vezes, este tipo de conflito é potencializado pela falta de participação pública no licenciamento ambiental de empreendimentos desta natureza. 


\section{Os municípios de Campina Grande e Puxinanã no contexto de conflitos ambientais}

Campina Grande apresenta não apenas uma importância no contexto da Paraíba, sendo o município mais importante do estado, após a capital, João Pessoa, mas também em âmbito nacional, sendo um importante polo tecnológico e educacional, formando e exportando profissionais de tecnologia da informática e de outras engenharias, bem como de áreas de saúde e humanas, além de atrair investimentos de multinacionais em projetos de pesquisa caracterizados como referência regional na área de tecnologia.

Em contraponto a esta realidade, Campina Grande foi marcada, ao longo de sua história, pela disposição final ambientalmente inadequada dos RSU. Até o mês de janeiro de 2012, os resíduos deste município eram destinados para lixões. Após a desativação do Lixão do Mutirão (bairro na periferia de Campina Grande), os RSU de Campina Grande passaram a ser dispostos no Aterro Sanitário de Puxinanã (ASP), localizado em município homônimo, na Paraíba, a $7 \mathrm{~km}$ de distância, aproximadamente. No quadro 1, são apresentadas características gerais relativas aos municípios de Campina Grande e Puxinanã.

Quadro 1: Características gerais dos municípios de Campina Grande e Puxinanã.

\begin{tabular}{|l|c|c|}
\hline \multirow{2}{*}{\multicolumn{1}{|c|}{ CARACTERÍSTICAS }} & Campina Grande & Puxinanã \\
\cline { 2 - 3 } & 407.754 & 13.638 \\
\hline População (hab.) & 648,31 & 177,81 \\
\hline Densidade demográfica $\left(\mathrm{km}^{2}\right)$ & 452 & 12 \\
\hline Geração de RSU (t.dia $\left.{ }^{-1}\right)$ & 1,23 & 0,5 \\
\hline Geração per capita de RSU (kg.hab ${ }^{-1}$. dia $\left.^{-1}\right)$ & Aterro Sanitário de Puxinanã & \\
\hline Disposição dos RSU até meados de 2015 & Aterro Sanitário de Campina Grande & Aterro Sanitário de Campina Grande \\
\hline Disposição dos RSU a partir de julho de 2015 &
\end{tabular}

Fonte: IBGE (2016); DANTAS (2013).

\section{Aterro Sanitário de Puxinanã}

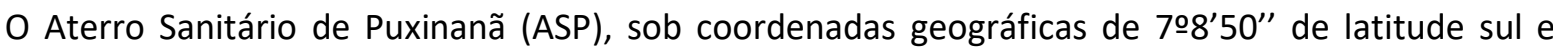
35 5 $58^{\prime} 43^{2}$ de longitude, a oeste do meridiano de Greenwich, localiza-se nas proximidades da área urbana de Puxinanã, a cerca de 800 m do Açude Evaldo Gonçalves (mais conhecido como Açude da Milhã) e a cerca de 1,5km da sede municipal. Foi implantado em 2012 para a disposição final dos RSU gerados em Puxinanã e áreas vizinhas.

A localização desfavorável onde foi instalado o ASP (cotas 695 a 660 m), em cota superior a do Açude da Milhã (630m), com toda a drenagem sendo direcionado à área desse reservatório; a falta de transparência e participação pública no processo de licenciamento deste aterro; os graves problemas operacionais relatados em parecer técnico da Superintendência de Administração do Meio Ambiente (SUDEMA, 2011) e a transferência de problema socioambiental do município de Campina Grande para Puxinanã geraram conflitos ambientais.

À época em que foi dada entrada no processo de solicitação para obtenção de Licença de Instalação (LI) do ASP, em dezembro de 2009, na descrição das atividades constava o pedido para atendimento de uma população estimada em 40.000 habitantes, envolvendo o município de Puxinanã e cidades vizinhas. Há de se considerar que não houve processo de solicitação para obtenção de Licença Prévia (LP). Em março de 2010 foi expedida a LI n $\mathrm{n}^{\circ} 483 / 2010$ para atendimento de uma população estimada de 450.000 habitantes, sem 
audência pública, o que catalizou todos os conflitos ambientais identificados nesta área de estudo; uma vez que a alteração na população atendida por este empreendimento tinha por finalidade a necessidade de disposição final dos RSU de Campina Grande, com mais de 400.000 habitantes no ASP.

Em março de 2010, foi aberto o processo de Licença de Operação (LO) do ASP. Em análise ao processo e vistoria no local, o órgão ambiental responsável verificou o discumprimento de 06 (seis) dos 14 (quatorze) condicionantes da LI, além de solicitação da LO sem terem concluídas as obras de instalação do ASP. Insatisfeita com o rumo do processo, a Prefeitura de Puxinanã conseguiu, por força de liminar concedida na forma de Mandado de Segurança, o imediato funcionamento do ASP; sendo emitida, em setembro de 2011, a LO N 2378/2011 do empreendimento, concedida por força de decisão judicial da 5a Vara da Fazenda Pública da Capital, ofício № 664/2011.

Em outubro de 2011, o Conselho de Proteção Ambiental (COPAM/SUDEMA), aprovou por unanimidade o não reconhecimento da LO N²378/2011, emitida por este órgão por ordem judicial, e recomendou encaminhar cópia do processo SUDEMA N 6504/10 ao Ministério Público Estadual (CAOP Meio Ambiente) para conhecimento e providências; bem como, que a SUDEMA em uma fiscalização conjunta com o IBAMA emitisse a lavratura de um auto de infração e do termo de embargo da operação do aterro (SUDEMA, 2011).

Apesar da postura do COPAM/SUDEMA, de não reconhecer a LO do ASP, a Prefeitura de Campina Grande assinou, em outubro de 2011, convênio de cooperação com a Prefeitura de Puxinanã, objetivando garantir a melhoria da malha viária entre os dois municípios e a destinação final provisória dos RSU de Campina Grande em Puxinanã.

Em função das características populacionais e consequente geração de RSU apresentadas no Quadro 1, o conflito que envolve o ASP tomou maiores proporções, uma vez que aproximadamente 95\% dos resíduos depositados neste aterro eram provenientes de Campina Grande; resultando numa alteração de deposição de aproximadamente 4.380 ton/ano para um adicional de 164.980 ton/ano, ou seja, um aumento de quase $3767 \%$ do que foi inicialmente planejado. Diante desta realidade, era prioritária a implantação de um aterro sanitário em território próprio de Campina Grande, em função da injustiça ambiental evidenciada pela exportação dos resíduos deste município para Puxinanã, sem qualquer benefício ou compensação para os munícipes dessa cidade.

Em paralelo a disposição dos RSU no ASP, tramitava-se processo de LO do Aterro Sanitário de Campina Grande (ASCG), empreendimento particular situado no distrito de Catolé de Boa Vista, Campina Grande, Paraíba. A operação do ASCG teve início em julho de 2015, sob LO N.o C9/2015. Atualmente, recebe resíduos de 05 (cinco) municípios, entres estes Campina Grande e Puxinanã, além dos resíduos de algumas empresas particulares.

\section{A dinâmica do conflito ambiental que envolve o Aterro Sanitário de Puxinanã}

Os conflitos são dinâmicos por natureza e abarcam toda uma complexidade em uma perspectiva tridimensional (cognitiva, emocional e comportamental), conforme definida por Mayer (2000). Sendo assim, 
um conflito, quando não tratado de maneira adequada, pode crescer e mudar. Muitos conflitos se desenvolvem a partir do inesperado, de um simples mal entendido. Outros surgem devido a uma mudança imprevista nas circunstâncias que surgem como um choque para algumas partes ou a totalidade de uma comunidade.

Segundo Fonseca et al. (2012), os conflitos "estão inseridos em uma temporalidade, podendo-se estender por anos e até por séculos, ou mesmo durar apenas algumas horas". Fonseca et al. (2012) ainda relatam que um conflito "pode em determinados períodos, ser mais ou menos intenso, e às vezes até se encontrar invisível aos olhos dos atores envolvidos". Em função desta dinâmica, o estudo do ASP tem sido reportado em duas fases:

Fase I, antes da desativação do ASP, período no qual os RSU de Campina Grande eram depositados neste aterro. Neste contexto, Autor (2017) analisou o conflito ambiental no âmbito do ASP, no período compreendido entre os anos de 2009 e 2014, através da aplicação de metodologias de análise de conflitos; e

Fase II, após a desativação do ASP e consequente disposição dos RSU de Campina Grande e Puxinanã no ASCG, a partir de meados de 2015; analisada neste artigo.

\section{RESULTADOS E DISCUSSÃO}

Em função da dinâmica natural dos conflitos, o estudo de caso relativo ao Aterro Sanitário de Puxinanã (ASP) foi dividido em uma escala temporal, conforme ilustrada na Figura 1, com destaque para a problemática central em cada fase definida. Esta estruturação ao longo do tempo é imprescindível, pois os desdobramentos de um conflito podem torná-lo mais ou menos intenso, ou até mesmo "adormecido" perante os atores envolvidos.

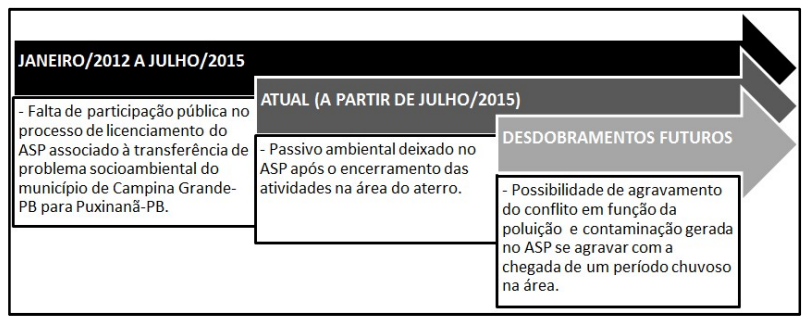

Figura 1: Escala temportal do conflito ambiental referente ao ASP.

O cenário atual em que se encontra o caso em estudo, de uma maneira geral, aponta para uma situação de um conflito menos intenso (latente), mas não menos complexo. A disposição dos RSU de Campina Grande em área própria deste município e a desativação do ASP, com a consequente destinação dos RSU de Puxinanã para o Aterro Sanitário de Campina Grande (ASCG), acabaram camuflando, de certa forma, o problema central relativo à fase inicial do conflito: falta de participação pública no processo de licenciamento do ASP e transferência de problema socioambiental, apontados na escala temporal da figura 1.

Por meio da aplicação de metodologias de análises de conflitos, foi possível compreender a nova dinâmica que permeia o estudo de caso relativo ao ASP, as tensões que envolvem os atores envolvidos, a formação de novas coalizões bem como a reestruturação deste conflito a partir do cenário atual. O conflito ambiental encontra-se pautado em uma nova problemática central: o passivo ambiental deixado na área do 
ASP. No intuito de situar o leitor a respeito da área de implantação do ASP, foi confeccionado o quadro 2, no qual são levantados pontos pertinentes relativos ao desempenho ambiental do aterro em análise.

Quadro 2: Aspectos relacionados à área de estudo, pertinentes a análise do conflito.

\begin{tabular}{|l|c|c|l|l|}
\hline \multicolumn{1}{|c|}{ ASPECTOS ANALISADOS } & SIM & NÃO & \multicolumn{1}{c|}{ OBSERVAÇÕES } \\
\hline Deposição de resíduos na área? & & $\mathrm{X}$ & Aterro desativado em julho de 2015. \\
\hline Permitido acesso de catadores? & & $\mathrm{X}$ & $\begin{array}{l}\text { Em visita realizada no entorno da área do ASP, em julho de 2016, não foi } \\
\text { constatada a presença de catadores. }\end{array}$ \\
\hline Cobertura dos resíduos? & & $\mathrm{X}$ & Grande parte dos resíduos está depositada a céu aberto. \\
\hline Drenagem de águas pluviais? & $\mathrm{X}$ & $\begin{array}{l}\text { Não há elementos de drenagem no maciço sanitário, como descidas d'água, } \\
\text { canaletas. }\end{array}$ \\
\hline Drenagem do lixiviado gerado? & $\mathrm{X}$ & $\begin{array}{l}\text { Em visita realizada no entorno da área do ASP, em julho de 2016, foi possível } \\
\text { visualizar "córregos" de lixiviado através dos taludes do maciço sanitário. }\end{array}$ \\
\hline Existência de drenos de biogás? & $\mathrm{X}$ & & $\begin{array}{l}\text { Apesar da existência de drenos, alguns se encontram mal executados e o } \\
\text { biogás está sendo lançado direto na atmosfera. Além do mais, há de se } \\
\text { considerar que existem drenos em locais em que os resíduos estão a céu } \\
\text { aberto. }\end{array}$ \\
\hline $\begin{array}{l}\text { Arborização em torno da área } \\
\text { (cinturão verde)? }\end{array}$ & $\mathrm{X}$ & $\begin{array}{l}\text { Há a presença de vegetação rasteira, típica do agreste paraibano, mas nenhum } \\
\text { projeto específico que contemple a área do entorno do ASP. }\end{array}$ \\
\hline $\begin{array}{l}\text { Proximidade de recursos } \\
\text { hídricos? }\end{array}$ & $\mathrm{X}$ & \begin{tabular}{l} 
A distância entre o ASP e o açude da Milhã é inferior a 1 Km. \\
\hline Proximidade de residências?
\end{tabular} & $\mathrm{X}$ & $\begin{array}{l}\text { Residências próximas ao ASP, a menos de 500 m, não foram indenizadas. } \\
\text { Houve desvalorização das terras, além da inutilização de tanques de água no } \\
\text { entorno, devido à presença de urubus. }\end{array}$ \\
\hline $\begin{array}{l}\text { O local pode ser considerado um } \\
\text { aterro sanitário conforme a NBR } \\
8419 / 1984 ?\end{array}$ & $\begin{array}{l}\text { Não apresenta: recobrimento intermediário dos resíduos; cobertura final das } \\
\text { plataformas de resíduos; coleta, drenagem e tratamento de lixiviados; } \\
\text { tratamentos dos gases; drenagem superficial; monitoramento ambiental. }\end{array}$ \\
\hline $\begin{array}{l}\text { Existe projeto de encerramento } \\
\text { das atividades? }\end{array}$ & $\begin{array}{l}\text { Não foram identificadas medidas de remediação da área em visita realizada } \\
\text { em julho de 2016. }\end{array}$ \\
\hline
\end{tabular}

Os aspectos apontados no Quadro 2 descaracterizam o ASP como um aterro sanitário, uma vez que este não cumpre sua função ambiental. À população de Puxinanã restou o passivo ambiental: parte dos resíduos dispostos no ASP não foi aterrada, há lixiviado escorrendo nos taludes do aterro e o biogás está sendo lançado na atmosfera (Figura 2).

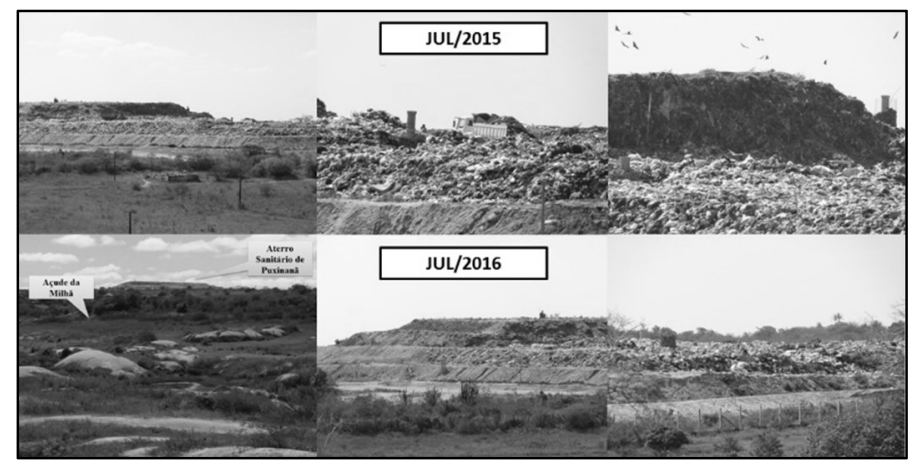

Figura 2: Vista do ASP em julho de 2015 e julho de 2016.

Há de considerar que o cenário atual aponta para agravamentos deste conflito no futuro, uma vez que após um longo período de escassez hídrica, de mais de 4 (quatro) anos, a perspectiva da chegada de um período chuvoso na região maximizaria o problema, em função do carreamento mais acentuado da poluição gerada no ASP para o Açude da Milhã, em cota de aproximadamente $40 \mathrm{~m}$ abaixo da cota do aterro. 
Estruturação inicial: dinâmica do conflito ambiental antes e após o fechamento do Aterro Sanitário de Puxinanã

A estruturação do conflito ambiental, antes e após o fechamento do ASP é apresentada na figura 3. Salienta-se que esta é a interpretação dos autores quanto aos fatos investigados. Na realidade, os atores envolvidos em um conflito muitas vezes nem sabem que são participes do mesmo. Em ambas as escalas temporais, não foram adotadas medidas de resolução do conflito que proporcionassem a restauração de uma relação positiva entre os atores. Percebe-se também que o cenário atual se apresenta com menos força, sem mobilizações por parte da população de Puxinanã, se configurando como uma situação de conflito 'adormecido'.

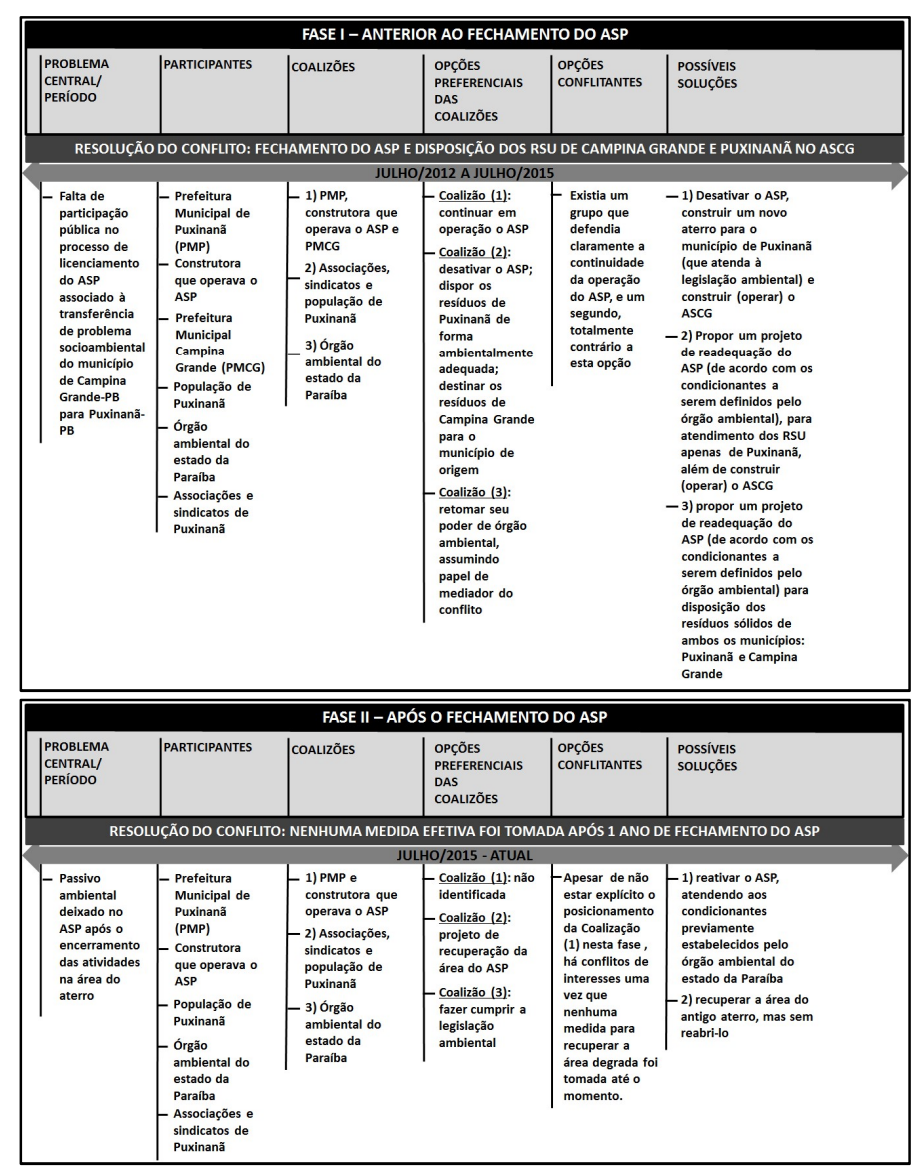

Figura 3: Estruturação do conflito antes e após o fechamento do ASP.

\section{Análise da cadeia causal do conflito ambiental antes e após o fechamento do ASP}

As causas e as inter-relações entre as mesmas são apresentadas para o conflito estudado (Figura 4). O aspecto ambiental que permeia este conflito está relacionado, diretamente, com a disposição final dos RSU dos antigos lixões localizados no entorno de Puxinanã, pertencente ao denominado Compartimento da Borborema-PB. Vale ressaltar que o fechamento do Lixão do Mutirão, onde os RSU de Campina Grande eram depositados, configurou-se como causa imediata precípua para o desencadeamento do conflito do ASP.

O principal setor envolvido foi a Prefeitura de Puxinanã, juntamente com a empresa que operava o ASP, pela instalação e operação de um aterro ambientalmente inadequado que não atendia às normas ambientais. Essa responsabilidade é compartilhada com o órgão ambiental do estado, pois apesar de não 
reconhecer a LO do empreendimento (expedida por força de lei), falhou no processo de licenciamento ambiental em fases anteriores, LP e LI. O gerenciamento inadequado da instalação e operação do ASP, aliado à falta de monitoramento pelos órgãos competentes, resultou na transformação do ASP em um vazadouro a céu aberto e este cenário ocasionou, posteriormente, o fechamento do aterro.

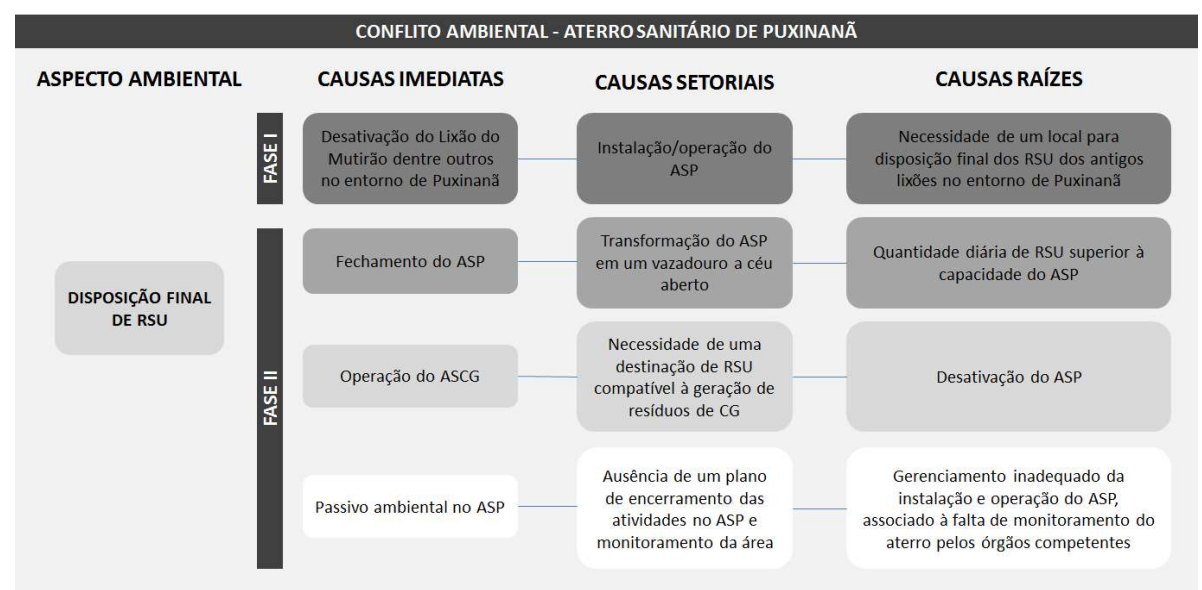

Figura 4: Cadeia causal do conflito ambiental que envolve o ASP.

\section{Aplicação dos princípios institucionais de Ostrom à luz do conflito do ASP}

Em termos legais, os aspectos institucionais relativos à disposição final de RSU em aterros sanitários são muito claros. O aparato de leis, resoluções e normas relativo a essa temática é vasto; definindo claramente os limites para este tipo de atividade, que utiliza o solo, bem de uso comum, como local para tratamento dos resíduos sólidos. Por meio do resgate dos aspectos legais e das experiências passadas aplicados ao conflito em estudo, foi confeccionada a Figura 5, onde são aplicados os princípios de Ostrom (1990) ao caso do ASP.

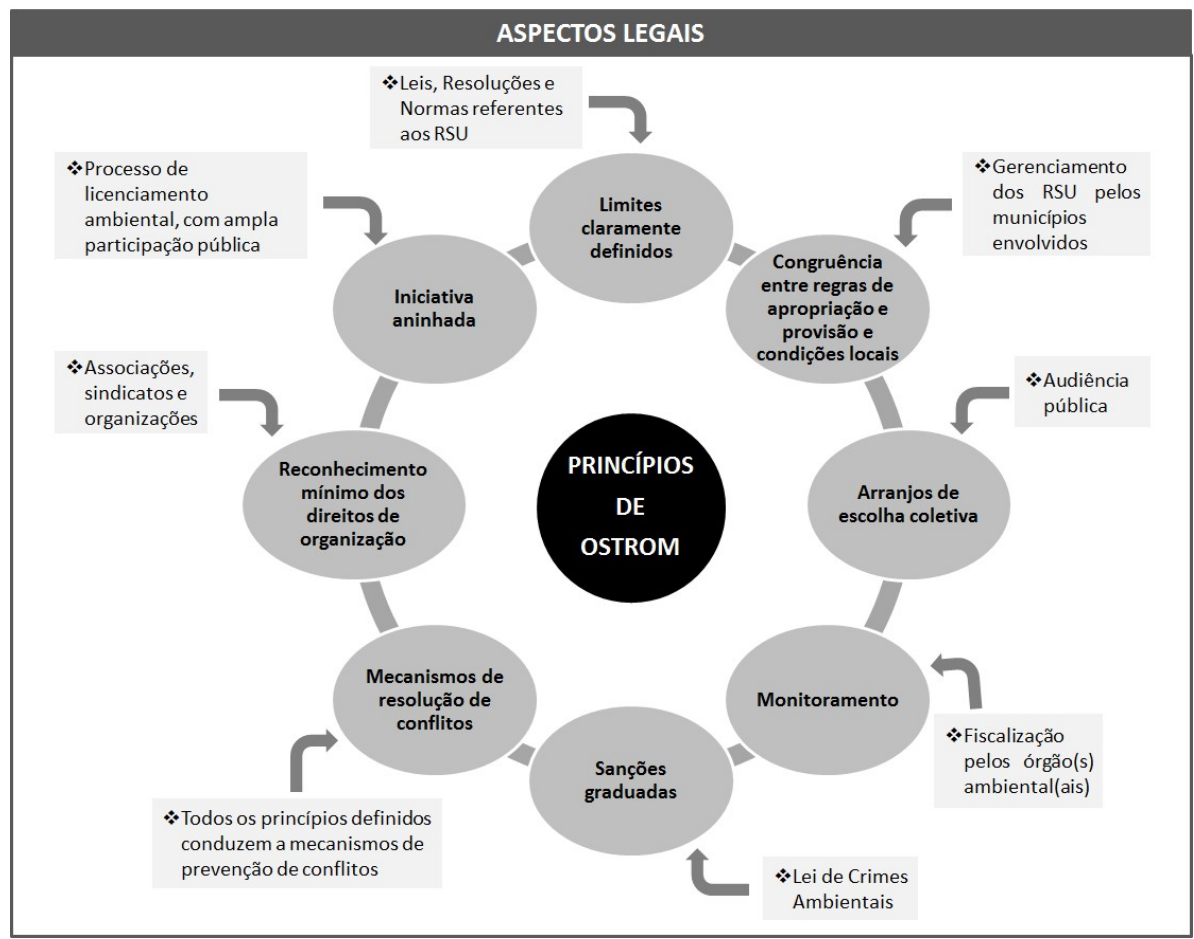

Figura 5: Aplicação dos princípios de Ostrom à luz dos aspectos legais relativos ao conflito. 
Embora os princípios institucionais de Ostrom sejam bem delineados para o caso em estudo, as experiências passadas referentes ao ASP apontam para uma fragilidade na aplicação destes princípios, o que justifica os recorrentes conflitos naquela área. Avaliando os princípios de Ostrom à luz do conflito ambiental referente ao ASP, pode-se concluir que:

Apesar dos limites claramente definidos, incluindo todo o aparato legal, estes não têm sido respeitados, uma vez que: (a) a etapa de LP foi negligenciada, fase na qual deveria ter sido analisado exaustivamente o EIA/RIMA, aprovando ou não a localização do empreendimento; (b) a concessão de LI mesmo com o EIA/RIMA apresentando erros grosseiros, dentre estes afirmando que o município de Puxinanã está situado na região Litorânea Nordestina; (c) a emissão da LO por força de decisão judicial, apesar de ter sido detectado o não cumprimento de condicionantes relativos à LI pelo órgão ambiental responsável;

O gerenciamento dos resíduos sólidos nos municípios em estudo tem sido direcionado de forma ao atendimento de interesse políticos imediatistas;

O arranjo de escolha coletiva tem sido ignorado. A falta de participação pública no processo de licenciamento ambiental do empreendimento catalisou ainda mais as tensões que envolvem este conflito;

Após o fechamento do ASP não tem sido notório a ação do órgão ambiental no sentido de monitorar a área degradada e delegar aos responsáveis pela agressão ambiental o dever de recuperá-la;

Não foram identificadas ações no sentido de sanções quanto ao descumprimento das regras ambientais e de todo o passivo ambiental deixado na região, que vem prejudicando os recursos naturais do município de Puxinanã;

Todos os aspectos supracitados, se tivessem sido direcionados de acordo com os aspectos legais que permeiam o caso, poderiam ter resultado na não geração de conflitos no ASP desta natureza ou, ao menos, minimizado os conflitos gerados. Depois do conflito gerado, os mecanismos de resolução têm se pautado em soluções superficiais, como forma de contornar o conflito. Tal afirmativa é contundente quando se observa o embargo do ASP há mais de um ano, sem medidas efetivas de recuperação da área degradada;

A fraca governança urbana tem resultado em um reconhecimento mínimo (ou mesmo o não reconhecimento) dos direitos de organização da população de Puxinanã; e

A apropriação, provisão, monitoramento, cumprimento, solução de conflitos e atividades de governança relacionadas à disposição final de RSU em aterros sanitários são organizados em multicamadas de iniciativas aninhadas, devendo envolver os diversos atores sociais da área direta e indireta afetada por esses empreendimentos. Este tipo de governança não foi empregado para o caso do ASP.

\section{Modelagem conceitual do conflito relacionado ao ASP}

A aplicação das metodologias de análise de conflitos discutidas forneceu dados de entrada para a confecção do mapa mental do conflito, conforme se nota na figura 6. Esta ferramenta é de fundamental importância em "rodas" de negociação para se chegar a alternativas de consenso entre as partes, visto que é uma forma rápida e simples de compreender os desdobramentos do conflito no tempo. Por fim, foi desenvolvido um modelo conceitual para o conflito relacionado ao ASP (Figura 7), passível de ser expandido para situações semelhantes, suscitando em uma ferramenta de suporte à tomada de decisão pelos mediadores. 


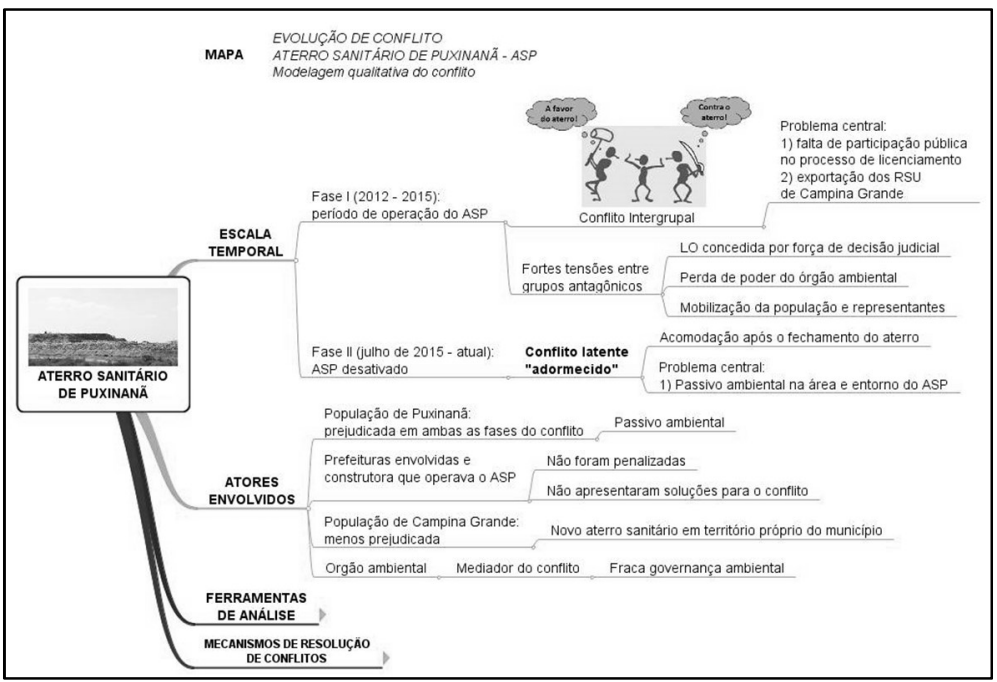

Figura 6: Modelagem qualitativa do conflito do ASP, por meio do InteliMap ${ }^{\circledR}$ (detalhamento da escala temporal e atores envolvidos).

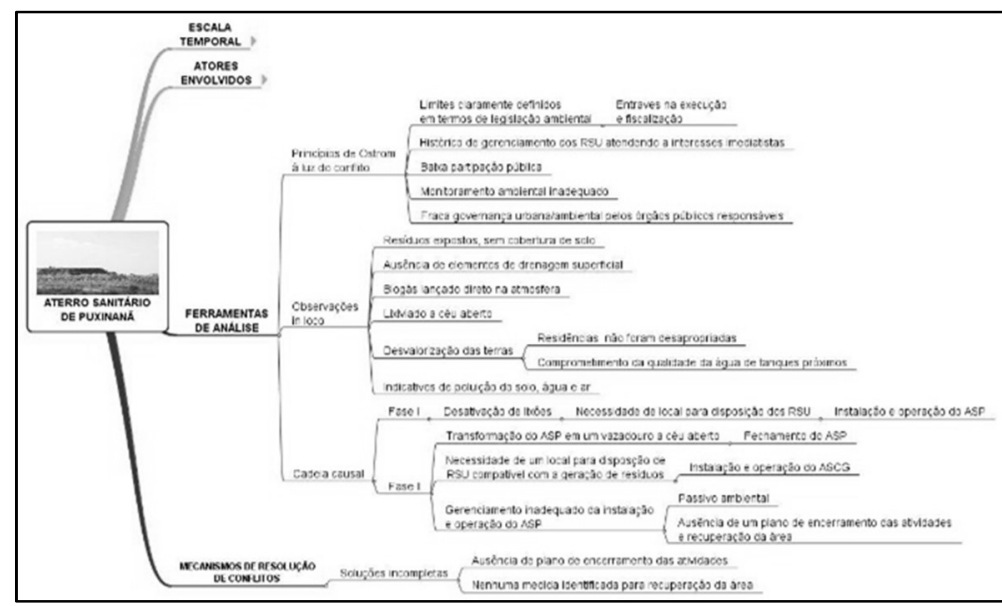

Figura 6: Modelagem qualitativa do conflito do ASP, por meio do InteliMap ${ }^{\circledR}$ (detalhamento das ferramentas de análise e mecanismos de resolução de conflitos) - continuação.

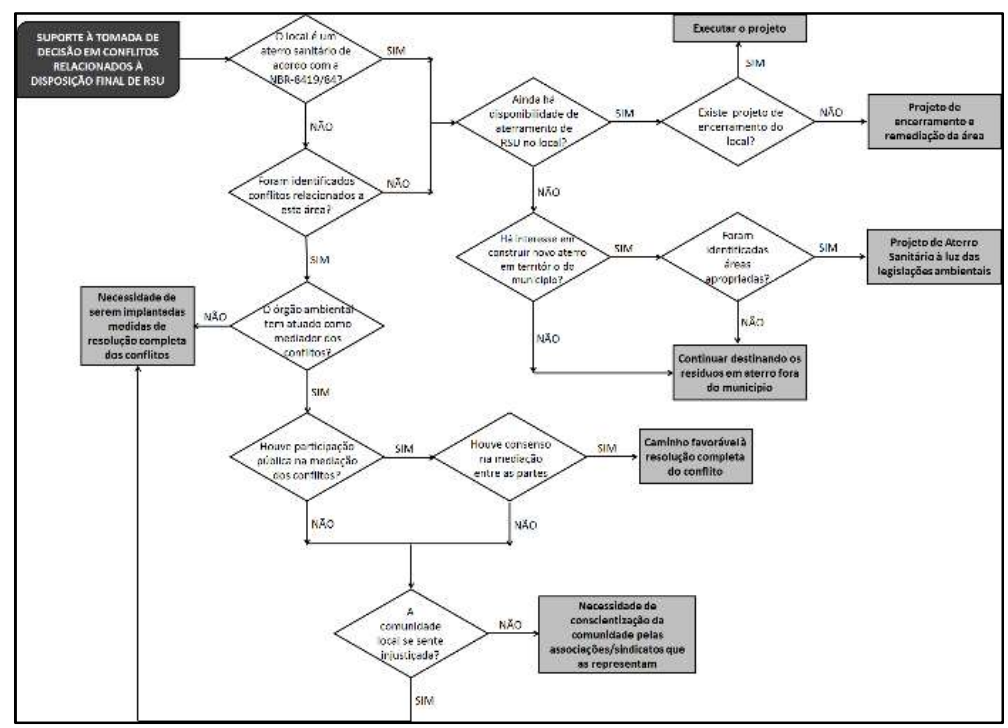

Figura 7: Modelagem conceitual de suporte à tomada de decisões em conflitos relacionados à disposição final de RSU.

\section{CONCLUSÕES}

Por meio das metodologias utilizadas para a análise da evolução do conflito do Aterro Sanitário de Puxinanã (ASP), pode-se concluir que: 
O conflito referente ao ASP, antes da desativação do aterro, resultou em uma solução incompleta deste;

A desativação do ASP, há mais de um ano, sem um plano de encerramento de suas atividades e consequente recuperação da área degradada tem evidenciado a fragilidade da governança urbana/ambiental pelos órgãos públicos responsáveis;

A população de Puxinanã-PB tem sido prejudicada em ambas as fases do conflito; na Fase II (após a desativação do ASP) estas perdas estão relacionadas ao passivo ambiental na área e entorno do empreendimento. Este passivo gera e continuará gerando, por muitas décadas, a deterioração dos sistemas ambientais (água, solo e ar);

Os desdobramentos do conflito, e toda a complexidade que o permeia, não catalisou as tensões entre os atores envolvidos na Fase II do conflito;

A análise da Fase II demonstra que, provavelmente, nem todos os atores tem a consciência de que estão envolvidos no conflito; fato evidenciado, principalmente, pela ausência de engajamento por parte da população de Puxinanã-PB e representantes;

O município de Campina Grande-PB não tem sofrido com as consequências dos desdobramentos do conflito na Fase II, visto que o município está dispondo seus resíduos sólidos em local ambientalmente adequado;

A modelagem conceitual proporcionou um caminho inicial e balizador para as partes envolvidas entenderem a dinâmica do conflito, de forma simples; se configurando como uma ferramenta de reflexão e suporte à tomada de decisão pelos gestores.

\section{REFERÊNCIAS}

ABRELPE. Associação Brasileira de Limpeza Pública e Resíduos Especiais. Panorama dos Resíduos Sólidos no Brasil. São Paulo: ABRELPE, 2014.

BOBBIO, L.. Conflitti territoriali: sei interpretazioni. TeMA Journal of Land Use, Mobility and Environment, v.4, n.4, p.79-88, 2011.

BRASIL. Lei n.12305 de 02 de agosto de 2010. Institui a Política Nacional de Resíduos Sólidos, altera a Lei n.9605, de 12 de fevereiro de 1998, e dá outras providências. Brasília: DOU, 2010.

DANTAS, E. R. B.. Análise do processo de implementação e operação do aterro sanitário do município de Puxinanã-PB utilizando o sistema de indicador de sustentabilidade pressão-estado-impacto-resposta (P-E-I-R). Dissertação (Mestrado em Engenharia Civil e Ambiental) - Universidade Federal de Campina Grande, Campina Grande, 2013.

FONSECA, B. C.; OLIVEIRA, M. L. R.; SOUSA, D. R. N.. Conflitos ambientais: atores, causas e desdobramentos na Zona da Mata Mineira. Caminhos de Geografia, v.13, n.42, p.283299, 2012.
IBGE. Instituto Brasileiro de Geografia e Estatística. Cidades. Rio de Janeiro: IBGE, 2016.

LIM, J. S.; MISSIOS, P.. Does size really matter?: Landfill scale impacts on property values. Applied Economics Letters, v.14, p.719-723, 2007.

MARQUES, M.; HOGLAND, W.. GIWA Methodology Testing in the Baltic Region: Causal Chain Analysis. Rio de Janeiro: Report, 2000.

MAYER, B.. The dynamics of conflict resolution: a practioner's guide. São Francisco: John Wiley \& Sons, 2000. OSTROM, E.. Governing the Commons: The Evolution of Institutions for Colletive Action. New York: Cambridge University Press, 1990.

OWUSU, G.; OTENG-ABABIO, M.; AFUTU-KOTEY, R. L.. Conflicts and governance of landfills in a developing country city, Accra. Landscape and Urban Planning, v.104, 2012, p.105-113, 2005. DOI: http://10.1016/j.landurbplan.2011.10.005

SUDEMA. Superintendência de Administração do Meio Ambiente. Parecer técnico da comissão de EIA/RIMA. João Pessoa: SUDEMA, 2011. 